neoplasms have not been encountered so far in girls treated for excessive height, and it is also reassuring that after treatment the menses seem uneventful and fertility normal.

The mechanism by which oestrogens suppress skeletal growth is still unknown. Plasma growth hormone levels are not depressed, but there is some evidence that its peripheral effects are reduced. ${ }^{8}$ Epiphyseal closure is accelerated, but that is not the sole rate-limiting factor. In spite of our restricted knowledge hormonal therapy has become increasingly popular and has replaced orthopaedic and radiotherapeutic approaches. Epiphyseal stapling retains its place in dealing with assymmetrical growth, but irradiation has rightly been abandoned because of the risks of inducing osteosarcomata.

Girls faced with the prospect of exceptional height require sympathetic consideration. Effective therapy is available if the problem is appreciated sufficiently early. Our skill in providing help will no doubt improve as we develop greater understanding of the processes of puberty and skeletal growth.

1 Tanner J M et al Archives of Disease in Childhood $1975,50,14$

2 Wettenhall, H. N. B., and Roche, A. F., Australian Paediatric fournal,

1965, 1, 210.
3 Whitelaw, M. J., Acta Endocrinologica, 1967, 54, 473.

4 Frasier, S. D., and Smith, F. G. Jr., Fournal of Clinical Endocrinology and Metabolism, 1968, 28, 416 .

5 Schoen, E. J., et al., American Fournal of Diseases of Children, 1973, 125, 71 5 Schoen, E. J., et al., American fournal of Diseases of Children, 1973, 125, 71.
Herbst, A. L., Ulfelder, H., and Poskanzer, D. C., New England fournal
of Medicine, 1971, 284, 878.

7 Cutler, B. S., et al., New England Fournal of Medicine, 1972, 287, 628.

Wiedmann, E., and Schwartz, E., Fournal of Clinical Endocrinology and Metabolism, 1972, 34, 51 .

\section{Malaria in Africa}

According to the World Health Organization's latest six monthly report on the world malaria situation, some 269 million people in sub-Saharan Africa still live under its scourge, and an estimated 600000 children under 4 years of age die annually from the disease. Malaria is, indeed, the main cause of morbidity and mortality in the general population of much of Africa. Small scale antimalarial measures, mainly in urban areas, give some type of protection to about $17 \%$ of the population at risk, but in many ccuntries, including Nigeria, Angola, Mozambique, and the Congo $95-100 \%$ of the population receive no specific antimalarial treatment at all. ${ }^{1}$

This picture of malaria in Africa today is little different from that 20 years or more ago, when the W.H.O. made the disease a target for global eradication. Sadly, the same factors that diminished hope of eradicating malaria in the 1960s-limited resources, unfavourable ecological conditions, and insufficient health coverage-have proved the main obstacles to attempting the less ambitious target of large-scale malaria control operations in the 1970s. These are just the same factors that have militated against control of other infections like measles, tuberculosis, tetanus, and poliomyelitis, which, like malaria, are major causes of morbidity and mortality in childhood in Africa and for which, as for malaria, highly effective means for prevention and cure are available.

Extreme poverty and shortage of trained personnel impose severe constraints on medical services in most African states, and often a bad situation is rendered worse by tragic misuse of available resources. Though most people live in rural areas, where diseases like malaria have their most serious impact, medical services tend to be concentrated in the cities, to be curative rather than preventive, and to be provided mainly for the wealthier sections of the community. The new governments in Africa cannot with justice be held solely responsible for the unsatisfactory operation and inequitable distribution of their medical services. The political instability, disorganization of civil services, social upheaval, and deteriorating economic circumstances that so often followed independence did not encourage their development and reform. Foreign aid, sometimes on a generous scale, has not always been granted on a basis of real need; so it is hardly surprising that it has made little impression and has on occasion done harm by diverting indigenous resources from basic health services. Projects aimed at specific diseases have tended to achieve variable success in the short term only to fail because basic services proved inadequate to consolidate early gains or meet long term commitments. The need for aid unfettered by political strings remains-and has been increased in poor countries by recent trends in world economics; but prospects for aid have diminished except in countries such as Nigeria with their own oil wealth.

The steady flow of disaster reports from abroad, disseminated by the mass news media and often cynically manipulated for political ends, has desensitized the public conscience to the needs of the developing countries. Hardly a whisper of dissent was heard about the cut-back in overseas aid announced recently in the budget. The medical profession, preoccupied with problems in a faltering Health Service, bemused by the changing role of doctors in society, and beset with anxieties about economic security seemingly lacks any wish to become concerned in "other people's problems." In this climate of thought the latest information about malaria in Africa will evoke little public reaction and provoke little more than a shrug of regret from most doctors. Should we not admit this lack of concern? We might then develop a renewed, more realistic interest in developing countries and a fresh appraisal of our role in their affairs.

1 World Health Organization Weekly Epidemiological Record, 1975, 50, 53.

\section{Breast Cancer in Young Women}

About $10 \%$ of breast cancers occur in women under the age of 40 , but in Britain any one general practitioner is likely to see only two such cases in his career. ${ }^{1}$ In spite of the relative rarity of breast cancer in young women the disease presents special problems that merit careful consideration. The patients may be wanting to get married, they may be pregnant, they may have young children to care for, or they may be anxious to have further children. For these reasons the prognosis of the disease and the effect of pregnancy on the outcome must play a critical part in influencing the management of the patient.

Breast cancer in young women is widely believed to be biologically less favourable than that occurring in the elderly, and this view has led some clinicians to modify their treatment policy according to the patient's age. Though breast cancer behaves as a heterogeneous disease and treatment policies may have to be tailored to the individual patient, age is probably one factor that does not influence the nature of its course. As

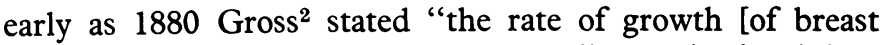
cancer] is not, contrary to the generally received opinion, influenced by the early age of the patient." A recent paper from America tends to support this view. ${ }^{3}$ The authors re- 